\title{
Different Expression Patterns of CXCR4, CCR7, Maspin and FOXP3 in Luminal Breast Cancers and Their Sentinel Node Metastases
}

\author{
LEENA STRIEN $^{1,2}$, KRISTIINA JOENSUU $^{1}$, PÄIVI HEIKKILÄ ${ }^{1,2}$ and MARJUT H. LEIDENIUS ${ }^{3}$ \\ ${ }^{1}$ Department of Pathology, Faculty of Medicine, University of Helsinki, Helsinki, Finland; \\ ${ }^{2}$ Department of Pathology, HUSLAB, and ${ }^{3}$ Breast Surgery Unit, Comprehensive Cancer Center, \\ Helsinki University Central Hospital, Helsinki, Finland
}

\begin{abstract}
Aim: Luminal A breast cancers $(B C)$ represent low-risk tumors conferring better outcome than luminal $B$ and human epidermal growth factor 2 (HER2)-positive or triplenegative tumors. One reason for the heterogeneous outcome among patients with luminal $B C$ is the variation in cell proliferation. As chemokine receptors and tumor suppressors show potential for estimation of infiltration to regional lymph nodes, we aimed to compare differently sized sentinel node metastases with their primary tumors (PT). Materials and Methods: We compared 29 BCs of luminal subtype A and 23 of subtype B (Ki-67 cut off at 14\%) by immunohistochemistry for the chemokine receptors $C-X-C$ chemokine receptor 4 (CXCR4), C-C-chemokine receptor 7 (CCR7), the tumor suppressor Maspin and the regulatory T-cell immunosuppressor forkhead box protein 3 (FOXP3) between PTs and their metastases of different size. Results: Expression of CXCR4 was low in luminal A type tumors, and CCR7 and FOXP3 expression were high in luminal $B$ type cancer. CXCR4 expression significantly positively correlated with CCR7 both in PTs and metastases. Most Maspin-positive PTs became negative in the metastases. The PTs for all Maspinpositive metastases were luminal B type. Conclusion: High CXCR4 expression in PTs was found to be associated with luminal A type tumor, suggesting more favorable outcome. In contrast, CCR7 and FOXP3 expressions in PTs represented luminal B tumors, pointing to more aggressive tumor behavior. Maspin expression did not differ between luminal types.
\end{abstract}

This article is freely accessible online.

Correspondence to: L. Strien, Haartmaninkatu 3, FIN-000029 HUS, Finland. Tel: +358 947182672, Fax: +358 947185912, e-mail: leena.strien@hus.fi

Key Words: Luminal breast cancer, sentinel node, micrometastasis, isolated tumor cells, CXCR4, CCR7, Maspin, FOXP3.
Luminal subtypes represent $80 \%$ of all breast cancers (BC) and can be further differentiated into luminal A and B type tumors based on Ki-67 immunohistochemistry (IHC) (1). In particular, luminal A type tumors are associated with relapse with longer latency than more aggressive BC types, such as human epidermal growth factor 2 (HER2)-enriched or basal/triple-negative BC (2).

Chemokines and their receptors, such as $\mathrm{C}-\mathrm{X}-\mathrm{C}$ chemokine receptor 4 (CXCR4) and C-C-chemokine receptor 7 (CCR7), have several roles in cancer development, including tumor growth, migration of tumor cells, metastasis to certain organs and angiogenesis. CXCR4 has especially been detected in several cancer tissues and related to metastasis formation in $\mathrm{BC}$ (3-5). Mueller et al. concluded that high expression of CXCR4 in BC may even guide tumor cells to the site of metastasis (4). High CXCR4 expression is also correlated with an increased number of lymph node (LN) metastases $(6,7)$. High CXCR4 expression characterizes $\mathrm{BCs}$ with unexpected aggressive behavior despite favorable clinical characteristics (8).

CCR7 mediates leukocyte migration during normal immune response in LNs.

Combined CXCR4 and CCR7 expression in BC enhances metastatic activity $(3,9)$. Blocking CCR7 hindered migration of BC cells (10). Cytoplasmic CCR7 expression in BC cells predicts LN positivity and has been associated with both CXCR4 and HER2 expression (6).

Maspin is a serine protease inhibitor originally associated with inhibiting angiogenesis and inducting apoptosis (11). On the other hand, Maspin expression characterizes a more aggressive phenotype of BC (12). Cytoplasmic Maspin expression is correlated with poor prognosis, while nuclear expression of Maspin is a more favorable feature $(13,14)$. However, there are only few studies reporting Maspin expression in regional LN metastases.

Subgroups of regulatory T-cells (Tregs) suppress tumor immune response in certain cancer types (15). Forkhead box protein 3 (FOXP3) is engaged in differentiation and 
Table I. Clinicopathological characteristics of the 52 patients divided by luminal A and B type of tumor.

\begin{tabular}{|c|c|c|c|c|}
\hline & Luminal $\mathrm{A}^{\dagger}(\mathrm{n}=29)$ & Luminal $\mathrm{B} \doteqdot(\mathrm{n}=23)$ & $p$-Value & Total $(\mathrm{n}=52)$ \\
\hline Mean age \pm SD (range), years & $60.8 \pm 10.2(44-90)$ & $54.7 \pm 12.0(32-86)$ & 0.087 & $57 \pm 11.4(32-90)$ \\
\hline Age $\leq 52$ years, $n$ & 5 & 11 & 0.018 & 16 \\
\hline Age $>52$ years, $n$ & 24 & 12 & & 36 \\
\hline Tumor size \pm SD (range), $\mathrm{mm}$ & $16.0 \pm 6.4(7-27)$ & $17 \pm 6.9(8-33)$ & 0.063 & $16.5 \pm 6.6(7-33)$ \\
\hline Metastasis size \pm SD (range), $\mathrm{mm}$ & $1.8 \pm 1.6(0.1-5)$ & $3.5 \pm 3.3(0.15-10)$ & 0.259 & $2.6 \pm 2.6(0.1-10)$ \\
\hline Macrometastasis, $\mathrm{n}$ & 13 & 9 & 0.850 & 22 \\
\hline Micrometastasis, $\mathrm{n}$ & 8 & 8 & & 16 \\
\hline ITCs, $\mathrm{n}$ & 8 & 6 & & 14 \\
\hline \multicolumn{5}{|l|}{ Pathology, n } \\
\hline Ductal & 22 & 19 & 0.626 & 41 \\
\hline Lobular & 2 & 2 & & 4 \\
\hline Other & 5 & 2 & & 7 \\
\hline \multicolumn{5}{|l|}{ Grade, $\mathrm{n}$} \\
\hline 1 & 15 & 5 & 0.001 & 20 \\
\hline 2 & 14 & 9 & & 23 \\
\hline 3 & 0 & 9 & & 9 \\
\hline \multicolumn{5}{|l|}{$\mathrm{ER}, \mathrm{n}$} \\
\hline $0(<10 \%)$ & 0 & 0 & 0.045 & 0 \\
\hline $1(10-39 \%)$ & 0 & 0 & & 0 \\
\hline $2(40-69 \%)$ & 0 & 3 & & 3 \\
\hline $3(70-100 \%)$ & 29 & 20 & & 49 \\
\hline \multicolumn{5}{|l|}{$\mathrm{PR}, \mathrm{n}$} \\
\hline $0(<10 \%)$ & 3 & 2 & 0.443 & 5 \\
\hline $1(10-39 \%)$ & 3 & 4 & & 7 \\
\hline $2(40-69 \%)$ & 9 & 3 & & 12 \\
\hline $3(70-100 \%)$ & 14 & 14 & & 28 \\
\hline \multicolumn{5}{|l|}{$\mathrm{Ki}-67, \mathrm{n}^{\S}$} \\
\hline $0(<5 \%)$ & 16 & 0 & 0.000 & 16 \\
\hline $1(5-14 \%)$ & 13 & 0 & & 13 \\
\hline $2(14-29 \%)$ & 0 & 17 & & 17 \\
\hline $3(>30 \%)$ & 0 & 6 & & 6 \\
\hline \multicolumn{5}{|l|}{ LVI } \\
\hline Present, $\mathrm{n}$ & 9 & 5 & 0.453 & 14 \\
\hline Absent, $\mathrm{n}$ & 20 & 18 & & 38 \\
\hline
\end{tabular}

ER: Estrogen receptor; PR: progesterone receptor; ITCs: isolated tumor cells; LVI: lymphovascular invasion (in hematoxylin-eosin). ${ }^{\dagger}$ Luminal A

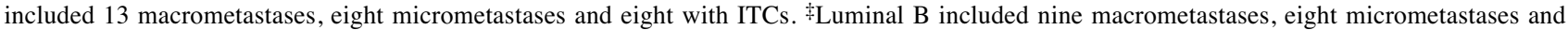
six with ITCs. ${ }^{\S}$ As detected by MIB-1. Chi-squared test was used, $p<0.05$.

activation of Tregs. In BC, FOXP3 expression correlates with progression and metastasis by modifying invasive properties (16). FOXP3 expression is associated with significantly worse prognosis in node-positive BC (17). Members of our group earlier found significantly higher FOXP3 positivity in T-lymphocytes in metastatic sentinel nodes (SNs) than in tumor-free $\mathrm{SNs}$, indicating local immunosupression mediated by Treg activation (18).

We investigated these four proteins in 52 node-positive BCs of luminal subtypes $\mathrm{A}$ and $\mathrm{B}$, as defined by immunohistochemical Ki-67-expression with a cut-off point of $14 \%$, including 14 cases with isolated tumor cells (ITC). We analyzed whether the expression of these factors differed between PTs and their SN metastases of different size, such as macro- and micrometastases, and ITCs. An important issue from a clinical point of view is to find indicators of more aggressive potential in this rather large, but prognostically incoherent tumor group. Another aim was to characterize if ITCs differ biologically from larger metastases.

\section{Materials and Methods}

Patient cases. The Breast Surgery Unit of the Helsinki University Hospital performed 1489 SN biopsies between August 2008 and April 2011. All cases with ITCs in this time period, $n=202$, were reviewed. Due to our previous experience of limited success in tissue retrieval from small-volume metastases (19), only cases with ITCs greater than $0.1 \mathrm{~mm}$ in size $(\mathrm{n}=25)$ were chosen for expression analysis. We randomly selected primary tumors (PTs) with 25 macroand 25 micrometastases for comparison. From these, 13 cases had to be excluded from final analysis due to technical reasons. 
Table II. Immunohistochemical list of antibodies, manufacturers and dilutions used in the immunohistochemical study.

\begin{tabular}{lccc}
\hline Antibody to & Microwave* & Manufacturer & Clone \\
\hline CXCR4 & Tris-EDTA & Enzo Life Sciences, Farmingdale, NY, USA & LS-B2160 \\
CCR7 & Tris-EDTA & Abcam, Cambridge, UK & MM 0067-9L11 \\
Maspin & Citrate buffer & BD PharMingen, Beckton Dickinson and & G167-70 \\
FOXP3 & Citrate buffer & Company, Franklin Lakes, NJ, USA & $1: 200$ \\
eBioscience, San Diego, CA, USA & PCH 101 & $1: 1000$ \\
\hline
\end{tabular}

Avidin-biotin complex (ABC) kits (Pk-6102, Pk-6103 and Pk-6104) by Vectastain (Vector Laboratories, Burlingame, CA, USA) were used*. TrisEDTA at $\mathrm{pH} 9.0$ and citrate buffer at $\mathrm{pH} 6.0$.

The final analysis included 52 cases, consisting of BCs with SN metastases, including 14 cases with ITCs, 16 with micrometastases and 22 with macrometastases. Macrometastases are defined $>2 \mathrm{~mm}$, micrometastases $>0.2 \mathrm{~mm}$ and $\leq 2 \mathrm{~mm}$, and ITCs $\leq 0.2 \mathrm{~mm}$. SN detection and workup was performed as described earlier (19). Clinical and histopathological information is given in Table I.

Molecular subtypes. Following Goldhirsch et al. (20), we used an IHC-based division of tissues into luminal A and B subtypes based on the molecular typing by Perou et al. (21). We used Ki-67 >14\% as cut-off point differentiating luminal $\mathrm{B}$ cases from luminal A cases as suggested by Cheang et al. (1). Ki-67 was determined in the tumor periphery at hot spot areas, including 400 cells. Our luminal B group did not include cases with strong (IHC $3+$ ) HER2 positivity or HER2 amplification by in situ hybridization.

Immunohistochemistry. Antibody clones, dilutions and detection antibodies are given in Table II.

The slides were deparaffinised in xylene and rehydrated in an alcohol series. Microwave heating in TRIS-EDTA ( $\mathrm{pH} 9.0) /$ citrate buffer ( $\mathrm{pH}$ 6.0) was applied for 20 minutes. The cooled slides were set in phosphate-buffered saline (PBS) $\times 3$ for 5 minutes and treated for 30 minutes with methanol-hydrogen peroxide for blocking endogenous peroxidase then whiled with PBS. Finally, antibodies to CXCR4, CCR7, Maspin and FOXP3 (Table II) were applied and slides were incubated overnight at $4^{\circ} \mathrm{C}$. The following day, the slides were first blocked with PBS and normal horse serum and secondly with Ig G (see Table II) for $30 \mathrm{~min}$ at room temperature according to the kit instructions. The slides were again washed with phosphatebuffered saline (PBS) and covered with the ABC kit reagents (see Table II) for 30 minutes at room temperature, followed by PBS.

The signals were visualized by diaminobenzene (DAB; Dako, Glostrup, Denmark) for 7 minutes, followed by counterstaining for 30 seconds with Mayer's haematoxylin and mounting. Appropriate control tissue (normal colon for CXCR4 and CCR7; normal breast tissue for Maspin; and a normal lymph node for FOXP3) was stained with every batch of 20 sections.

All cases were evaluated by light microscopy by a reader blinded to clinical parameters (L.S.). For each case, the expression in the PT was compared with that in the corresponding metastasis. Based on the literature available to date, the documentation included an evaluation of the staining pattern (cytoplasmic/nuclear/membranous and possible combinations). Staining intensity was scored as follows: none $=0$, weak $=1$, moderate $=2$, strong $=3$ (6). Expression was also documented as a percentage of the volume stained to total tumor volume.
For CXCR4 and CCR7, cytoplasmic staining $>50 \%$ was counted as high positive expression $(3,6), 25-50 \%$ as low positive expression, and $<25 \%$ as negative staining (3). CXCR4- and CCR7positive expression was defined as $\geq 25 \%$.

For Maspin, cytoplasmic/cytoplasmic and nuclear/nuclear staining $>10 \%$ was regarded as positive according to Joensuu et al. (14). For FOXP3, a cut-off of $>10 \%$ for positive expression was chosen according to Ladoire et al. (22).

Statistical analysis. Comparison between the expression of CXCR4, CCR7, Maspin and FOXP3 in PT and their metastases, and prognostic factors were analyzed by $\mathrm{Chi}^{2}$ test applying SPSS 22 version for Windows (IBM Corporation, Armonk, NY, USA). A value of $p \leq 0.05$ was regarded as significant.

\section{Results}

Clinicopathological variables. Fifty-two PTs and their corresponding SN metastases, consisting of 14 ITCs, 16 micrometastases and 22 macrometastases were analyzed. The median age of the patients was 57 years (range $=32-90$ years) (Table I). Nine patients (17.3\%) were under 50 years old, 22 patients $(42.3 \%)$ were 50 to 60 years old, and 21 patients $(40.3 \%)$ were over 60 years of age.

Median tumor size was $15 \mathrm{~mm}(7-33 \mathrm{~mm})$. Nine patients had poorly (grade=3) differentiated PTs. Expression of estrogen receptor (ER) was positive in all 52 cases and progesterone receptor (PR) in 47/52 (90\%) of cases. The median number of axillary sentinel nodes was 2 (range $=1$ 4). The prognostic factors did not differ according to the size of the SN metastases (data not shown).

Luminal subtypes $A$ and B. Using $14 \%$ as cut-off point for Ki-67, 29 tumors (56\%) were of luminal A subtype and 23 (44\%) were luminal B.

Patients with luminal A-type cancer were significantly older compared to those with luminal B-type $(p=0.018)$ (Table I). The majority of carcinomas were grade 1 and 2 (83 $\%$ ), and all nine grade 3 tumors were of luminal B subtype $(p=0.001)$ (Table I). The luminal B-type tumors had a tendency to be larger, but the difference was not significant $(p=0.063)$ (Table I). 
Table III. Comparison of $C$ - $X$ - $C$ - chemokine receptor 4 (CXCR4), $C$-C chemokine receptor 7 (CCR7), maspin and forkhead box protein 3 (FOXP3) expression between luminal A and luminal B breast cancer primary tumors.

\begin{tabular}{lcccc}
\hline & $\begin{array}{c}\text { Luminal A } \\
(\mathrm{n}=29,56 \%), \\
\mathrm{n}(\%)\end{array}$ & $\begin{array}{c}\text { Luminal B } \\
(\mathrm{n}=23,44 \%), \\
\mathrm{n}(\%)\end{array}$ & $\mathrm{N}$ & $p$-Value \\
\hline CXCR4 & & & & \\
Positive & $14(50)$ & $14(50)$ & 28 & 0.366 \\
Negative & $15(63)$ & $9(37)$ & 24 & \\
High & $11(65)$ & $6(35)$ & 17 & 0.053 \\
Low & $3(27)$ & $8(73)$ & 11 & \\
CCR7 & & & & \\
Positive & $8(35)$ & $15(65)$ & 23 & 0.007 \\
Negative & $21(72)$ & $8(28)$ & 29 & \\
High & $4(33)$ & $8(67)$ & 12 & 0.879 \\
Low & $4(36)$ & $7(64)$ & 11 & \\
Maspin & & & & \\
Positive & $13(59)$ & $9(41)$ & 22 & 0.680 \\
Negative & $16(53)$ & $14(47)$ & 30 & \\
FOXP3 & & & & \\
Positive & $16(46)$ & $19(54)$ & 35 & 0.036 \\
Negative & $13(77)$ & $4(23)$ & 17 & \\
\hline
\end{tabular}

Table IV. Comparison of $C$ - $X$ - $C$ - chemokine receptor 4 (CXCR4), $C$ - $C$ chemokine receptor 7 (CCR7), maspin and forkhead box protein 3 (FOXP3) expression between primary tumors (PTs) and corresponding metastases (MTs).

\begin{tabular}{|c|c|c|c|c|}
\hline \multirow[b]{2}{*}{ PT } & \multirow[b]{2}{*}{$\mathrm{N}$} & \multicolumn{2}{|c|}{ MT } & \multirow[b]{2}{*}{$p$-Value } \\
\hline & & Positive & Negative & \\
\hline \multicolumn{5}{|l|}{ CXCR4 } \\
\hline Positive & 28 & $21(75)$ & $7(25)$ & 0.006 \\
\hline Negative & 24 & $10(42)$ & $14(58)$ & \\
\hline Total & & 31 & 21 & \\
\hline \multicolumn{5}{|l|}{ CCR7 } \\
\hline Positive & 23 & $17(74)$ & $6(26)$ & 0.000 \\
\hline Negative & 29 & $7(24)$ & $22(76)$ & \\
\hline Total & & 24 & 28 & \\
\hline \multicolumn{5}{|l|}{ Maspin } \\
\hline Positive & 22 & $3(24)$ & $19(76)$ & 0.012 \\
\hline Negative & 30 & 0 & $30(100)$ & \\
\hline Total & & & & \\
\hline \multicolumn{5}{|l|}{ FOXP3 } \\
\hline Positive & 35 & $23(68)$ & $11(32)^{\mathrm{a}}$ & 0.025 \\
\hline Negative & 17 & $11(69)$ & $5(31)^{\mathrm{b}}$ & \\
\hline Total & & 34 & 16 & \\
\hline
\end{tabular}

${ }^{a}+1$ exclusion; ${ }^{b}+1$ exclusion.

CXCR4 expression. Twenty-eight PTs (54\%) were CXCR4positive, see Figure 1 as an example of CXCR4-expression. We found high cytoplasmic CXCR4 expression in 11/17 (65\%) luminal $\mathrm{A}$ and in 6/17 (35\%) luminal B tumors
Table V. Correlations between expression of $C$ - $X$ - $C$ - chemokine receptor 4 (CXCR4) and $C$-C-chemokine receptor 7 (CCR7), maspin and forkhead box protein 3 (FOXP3) in primary tumors (PTs).

\begin{tabular}{|c|c|c|c|c|c|}
\hline \multirow[b]{2}{*}{ PT } & & \multirow[b]{2}{*}{$\mathrm{N}$} & \multicolumn{2}{|c|}{$\mathrm{PT}$} & \multirow[b]{2}{*}{$p$-Value } \\
\hline & & & Positive (\%) & Negative (\%) & \\
\hline & & \multicolumn{4}{|c|}{ CCR7 } \\
\hline CXCR4 & Positive & 28 & $16(57)$ & $12(43)$ & 0.043 \\
\hline \multirow[t]{3}{*}{ CXCR4 } & Negative & 24 & $7(29)$ & $17(71)$ & \\
\hline & Total & & 23 & 29 & \\
\hline & & \multicolumn{4}{|c|}{ Maspin } \\
\hline CXCR4 & Positive & 28 & $11(39)$ & $17(61)$ & 0.460 \\
\hline \multirow[t]{3}{*}{ CXCR4 } & Negative & 24 & $11(46)$ & $13(54)$ & \\
\hline & Total & & 22 & 30 & \\
\hline & & \multicolumn{4}{|c|}{ FOXP3 } \\
\hline CXCR4 & Positive & 28 & $21(75)$ & $7(25)$ & 0.207 \\
\hline \multirow[t]{3}{*}{ CXCR4 } & Negative & 24 & $14(58)$ & $10(42)$ & \\
\hline & Total & & 35 & 17 & \\
\hline & & \multicolumn{4}{|c|}{ FOXP3 } \\
\hline Maspin & Positive & 22 & $14(64)$ & $8(36)$ & 0.059 \\
\hline \multirow[t]{3}{*}{ Maspin } & Negative & 30 & $21(70)$ & $9(30)$ & \\
\hline & Total & & 35 & 17 & \\
\hline & & \multicolumn{4}{|c|}{ Maspin } \\
\hline CCR7 & Positive & 23 & $11(48)$ & $12(52)$ & 0.410 \\
\hline \multirow[t]{3}{*}{ CCR7 } & Negative & 29 & $11(38)$ & $18(62)$ & \\
\hline & Total & & 22 & 30 & \\
\hline & & \multicolumn{4}{|c|}{ FOXP3 } \\
\hline CCR7 & Positive & 23 & $19(82)$ & $4(18)$ & 0.392 \\
\hline \multirow[t]{2}{*}{ CCR7 } & Negative & 29 & $16(55)$ & $13(45)$ & \\
\hline & Total & & 35 & 17 & \\
\hline
\end{tabular}

$(p=0.053)$. Low CXCR4 expression was detected in 11 (40\%) PTs. There were no differences between subtypes A and B in overall expression of CXCR4 ( $p=0.366)$ (Table III).

There were no significant differences in conventional prognostic factors including age, tumor size, size of the metastasis, ER or PR status, or lymphovascular invasion by hematoxylin-eosin or histological tumor type between CXCR4-positive and -negative PTs (data not shown).

CXCR4 positivity in metastases was either low or high in 31 cases (59\%). Twenty-one out of all 31 CXCR4-positive cases $(75 \%)$ were concordantly positive in both PT and metastases and 14/21 (58\%) of all negative cases were concordantly negative. The concordance between CXCR4positive in PTs and their metastases was significant ( $p=0.006$; Table IV). Cases with CXCR4-positive PT and metastasis showed a tendency to be of higher grade, although the difference was not significant ( $p=0.085$; data not shown).

In PTs, positive CXCR4 expression correlated significantly with positive CCR7 expression, 16/23 (70\%) were CCR7positive and 7/23 (30\%) cases were CCR7- negative $(p=0.043$, Table V). However, CXCR4 expression did not correlate with Maspin or FOXP3 expression (Table V). 


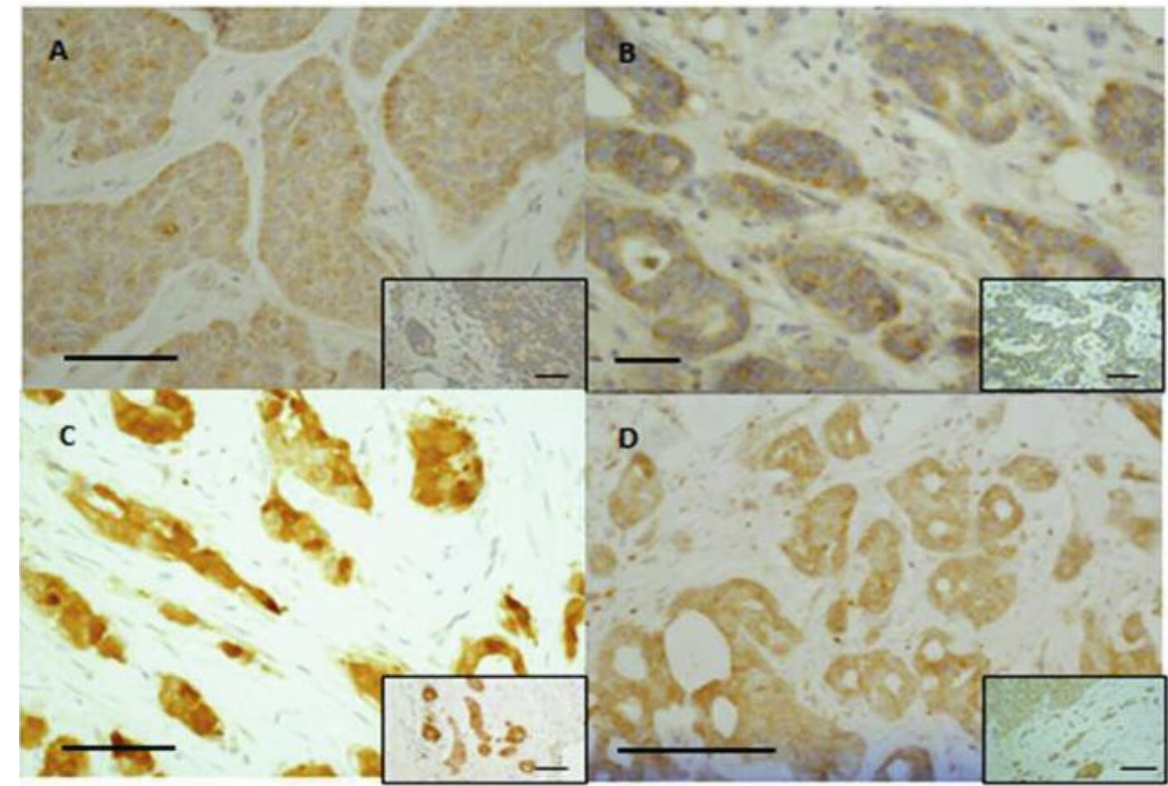

Figure 1. Examples of positive staining for $C$-X-C-chemokine receptor 4 (CXCR4) (A), C-C-chemokine receptor 7 (CCR7) (B), MASPIN (C) and forkhead box protein 3 (FOXP3) ( $D$ in primary breast tumors (main image) and their corresponding sentinel node metastases (inset). Scale bar $100 \mu \mathrm{m}$, in $\mathrm{D} 300 \mu \mathrm{m}$.

CCR7 expression. CCR7 was positive in twenty-three PTs (44\%) (Table III). Figure 1 presents an example for CCR7expression. CCR7 staining was cytoplasmic in all PTs and metastases. Low expression was detected in 11 (48\%) and high in $12(52 \%)$ PTs. Luminal B tumors were significantly more often CCR7-positive $(65 \%)$ vs. luminal A $(28 \%)$ $(p=0.007$, Table III). There were no significant differences in conventional prognostic factors between CCR7-positive and negative cases (data not shown).

Metastases were CCR7-positive in 24 cases (46\%). Seventeen out of these 24 cases were concordantly positive with the PT (74\%) $(p<0.0001$, Table IV). Patients older than 52 years more often had CCR7-positive metastases than patients younger than 52 years ( $p=0.025$, data not shown). All three CXCR4- and CCR7-positive PTs with concordantly CXCR4- and CCR7-positive metastases were luminal B cases $(p=0.034)$, while metastases from 10 luminal A tumors were concordantly negative (data not shown).

Maspin expression. Maspin expression was positive in $22(42 \%)$ PTs (Table III). Figure 1 presents an example for Maspinexpression. Maspin expression was cytoplasmic in seven (32\%) and nuclear in $15(68 \%)$ PTs. There were no significant differences in luminal subtype between Maspin-positive and negative cases. Thirteen luminal A (59\%) and nine luminal B (41\%) tumors were Maspin-positive ( $p=0.680$, Table III). There were no differences in conventional prognostic factors between Maspin-positive and -negative tumors (data not shown).
Subcellular staining did not show any significant differences by luminal subtype or metastasis size (data not shown).

Maspin expression was significantly lower in metastases ( $p=0.012$, Table IV). Metastases were negative for Maspin in 49 cases $(94 \%)$, with 30 concordantly Maspin-negative PTs. Three metastases of 22 Maspin-positive PTs remained Maspin-positive, all representing luminal type B tumors $(3 / 23,13 \% ; p=0.025$, data not shown). Only nuclear Maspin expression occurred in the metastases. One case changed subcellular expression from originally cytoplasmic in the PT to nuclear in the metastasis.

FOXP3 expression. FOXP3 expression was positive in 35 (67\%) patients (Table III). Figure 1 presents an example for FOXP3-expression. Nuclear expression dominated in 54\%, and $12 \%$ showed a combination of cytoplasmic and nuclear expression, while in $34 \%$ of tumors, the expression was purely cytoplasmic.

FOXP3-negative tumors were more frequent in luminal type A $(13 / 17,77 \%)$ than luminal type B $(4 / 17,23 \%)$ tumors $(p=0.036$, Table III).

Thirty-four (68\%) metastases were FOXP3-positive. Two (3\%) cases were excluded due to technical problems in staining the metastasis. The metastases stained concordantly positive with the PT in $23(46 \%)$ cases ( $p=0.025$, Table IV).

There was no correlation of FOXP3 expression with CXCR4 or CCR7 expression, despite a trend for FOXP3positivity in Maspin-negative tumors (Table V). 


\section{Discussion}

Luminal subtypes $A$ and $B$. Patients with luminal A type cancer were significantly older than patients with luminal Btype, with a mean age of 60.8 years versus 54.7 years, respectively. Similar findings were described by Kennecke et al. in a larger patient series (2). We also found that tumor grade was significantly higher in luminal B than in luminal A tumors, as described earlier (2). In our material, all luminal A tumors were either grade 1 or 2 , and about onethird of luminal B tumors were grade 3 .

CXCR4. In our study, 54\% of PTs were positive for cytoplasmic CXCR4 expression. Other studies have shown variable CXCR4 expression, ranging between $41 \%$ and $77 \%$, but in these series, HER2-positive and triple-negative cases were also included (3, $5,23,24)$. In our material, CXCR4 expression in luminal B tumors was lower than in luminal A tumors.

Several studies including one meta-analysis have shown CXCR4 expression to correlate with axillary LN metastases $(3,5,6,25-27)$. In our study, a high, significant concordance (75\%) between CXCR4-positive PTs and their metastases existed. Similarly, Liu et al. reported $100 \%$ concordance between PTs and axillary metastases (3). Interestingly, Cabioglu et al. showed CXCR4 positivity most often in tumors with bone metastases (27), suggesting CXCR4 to contribute to homing of breast cancer cells to bone.

The findings concerning CXCR4 positivity and traditional clinicopathological parameters in previous studies are discordant $(5,23,25)$. We were unable to find any correlation between CXCR4 and tumor grade, ER, and HER2 expression. Similar results were also obtained in a larger meta-analysis (7).

CXCR4 overexpression in BC correlates with worse prognosis and decreased survival $(7,23,28)$, possibly implicating a more aggressive subgroup among luminal carcinomas. However, in our material with node-positive BC, we did not find differences in CXCR4 expression between luminal A and B subtypes.

CCR7. We found positive CCR7 expression in $44 \%$ of PTs. Other investigators reported similar results with $57-84 \%$ CCR7 positivity in their cases $(3,27)$. Interestingly, our luminal B tumors showed significantly more CCR7 positivity than luminal A tumors, which could reflect a more aggressive phenotype. CCR7 expression has been correlated to more aggressive tumor features, such as LN metastases (6, 27) and decreased survival (3).

To our knowledge, only Liu et al. and we have analyzed CCR7 in regional LN metastases, our result (74\%) concur with that of Liu et al. (77\%) (3). Cabioglu et al. studied the correlation between PT and distant metastasis and found a lower concordance (33\%) (27).
In our study, all cases with CXCR4- and CCR7-positive PTs and concordantly positive metastases were luminal B tumors, possibly indicating a more aggressive disease course. Cooperation of CXCR4 and CCR7 in close association with their respective ligands have been reported to be responsible for anoikis, meaning reduced sensitivity to apoptosis normally caused by detachment of neoplastic cells from cellcell and cell-matrix contacts (29). This may implicate enhanced survival of mobile cancer cells in circulating blood or extracellular matrix.

Maspin. Maspin was originally considered to be a tumor suppressor (30) but recent studies have shown this prognostic role to correlate with nuclear or cytoplasmic subcellular localization (14). In our material, $42 \%$ of PTs were Maspinpositive. Subcellular Maspin expression was located in the nucleus in $68 \%$ and cytoplasm in $32 \%$ of cases, without any difference in subcellular location between PTs of luminal A and B type.

In the largest IHC study, including 1068 patients with BC, Mohsin et al. reported nuclear Maspin expression in $96 \%$ of tumors and cytoplasmic expression in 35\% (13). In that study, nuclear expression was strongly associated with better prognostics factors such as positivity for hormone receptors. Several studies have shown cytoplasmic Maspin to be associated with more aggressive tumor features such as negativity for hormone receptors, higher Ki-67 index and aneuploidy $(13,14)$ larger tumor size, higher tumor grade and positivity for p53 (12).

In this study, Maspin expression was significantly reduced in the metastases compared with PTs. This finding is in agreement with a study by Maass et al. showing loss of Maspin expression from PTs to LNs (31). Data obtained from cultured cells suggest that DNA methylation or histone deacetylation are partially responsible for the silencing of Maspin gene expression (32).

Interestingly, all our luminal A tumors had Maspinnegative metastases and all three Maspin-positive metastases were from luminal B tumors and presented nuclear expression. These results are in line with Joensuu et al. reporting of significantly higher Maspin-expression in late compared to early relapsing tumors (14). Studies with $\mathrm{BC}$ cell lines have shown epigenetic silencing of Maspin in luminal A-like BC (33). In addition, Vecchi et al. demonstrated that Maspin was one of the few genes discriminating PTs from their corresponding metastases (34), suggesting that metastases are molecularly different from their PTs.

FOXP3. In our material, FOXP3 expression was detected in $67 \%$ of the PTs. This is in line with $20-73 \%$ found by other investigators measuring FOXP3 expression in BCs by IHC $(17,22,35,36)$. 
The subcellular location of a protein is related to function especially in the case of FOXP3, which as a transcription factor originally was believed to be limited to a nuclear location (37). In tumor cells, cytoplasmic localization has been explained by failure in translocation to the nucleus $(35,38)$. In our study, luminal B tumors were more often FOXP3-positive than were luminal A tumors. Predominance of nuclear FOXP3 location in our material might be explained by exclusively ER-positive, HER2negative PTs, as nuclear FOXP3 expression has been associated with ER-positive PTs and a favorable clinical outcome (39).

In previous reports, FOXP3 positivity has been associated with higher tumor grade, higher Ki-67 expression and LN metastases $(17,39,40)$. In these studies FOXP3 expression was mostly cytoplasmic or combined cytoplasmic/nuclear.

Cell culture studies have shown FOXP3 overexpression to correlate with decreased expression of HER2, S-phase kinaseassociated protein 2 (SKP2), cellular myelocytomatosis oncogene $(c-M Y C)$ and CXCR4. In contrast, specific knockdown of FOXP3 in normal breast epithelial cells increased HER2, SKP2, c-MYC and CXCR4 expression (37). These results suggest FOXP3 functions as a tumor suppressor in BC.

Metastatic potential might be due to binding of FOXP3 to the gene region upstream of the closely situated transcription start sites of CXCR4 and CCR7 (17).

\section{Conclusion}

Our 29 luminal A and 23 luminal B BCs showed cytoplasmic CXCR4 and CCR7 in both PTs and SN metastases. Previous research suggests that $\mathrm{CXCR} 4$ and $\mathrm{CCR} 7$ positivity points to a more aggressive disease course, which according to our results was shown for CCR7 only. Chemokine receptors have seldom been analyzed in PTs and their corresponding small metastases.

Maspin positivity was more frequently nuclear than cytoplasmic. This result support nuclear Maspin having a role as a tumor suppressor.

LN metastases were significantly less frequently Maspinpositive than PTs. All Maspin-positive metastases were from luminal B tumors and the expression was nuclear.

Luminal B tumors were more often FOXP3-positive suggesting a more aggressive behavior.

Analyzing the expression of these factors in LNs could represent another way to analyze tumor behavior, since earlier studies with these biomarkers have shown more aggressive tumor behavior. Further research is needed to determine whether these factors may play a role in the phenomenon of tumor dormancy.

The origin and clinical significance of ITCs has been often debated after their increased incidence was found in SN studies. The results of this report suggest that ITCs and micrometastases are a continuum and do not represent separate processes.

\section{References}

1 Cheang CU, Chia SK, Voduc D, Gao D, Leung S, Snider J, Watson M, Davies S, Bernard PS, Parker JS, Perou CM, Ellis MJ and Nielsen TO: Ki 67 Index, HER-2 status, and prognosis of patients with luminal B breast cancer. J Nat Cancer Instit 101(10): 736-750, 2009.

2 Kennecke H, Yerushalmi R, Woods R, Cheang MCU, Voduc D, Speers CH, Nielsen TO and Gelmon K: Metastatic behaviour of breast cancer dubtypes. J Clin Oncol 20: 3271-3277, 2010.

3 Liu Y, Li J, Gu X, Zhao X, Sun T, Wang J, Li J, Du Q and Sun B: Correlation effect of EGFR and CXCR4 and CCR7 chemokine receptors in predicting breast cancer metastasis and prognosis. J Exp and Clin Canc Res 29: 16-25, 2010.

4 Mueller A, Homey B, Soto H, Ge N, Catron D, Buchanan ME, Mc Clanahan T, Murphy E, Yuan W, Wagner SN, Barrera JL, Mohar A, Verástegui $\mathrm{E}$ and Zlotnik A: Involvement of the chemokine receptors in breast cancer metastasis. Nature 410: 50$56,2001$.

5 Yasuoka H, Tsujimoto M, Yoshidome K, Nakahara M, Kodama R, Sanke T and Nakamura Y: Cytoplasmic CXCR4 Expression in breast cancer: induction by nitric oxide and correlation with lymph node metastasis and poor prognosis. BMC Cancer 8: 340350, 2008.

6 Cabioglu N, Yazici MS, Arun B, Broglio KR, Hortobagyi GN, Price JE and Sahin A: CCR7 and CXCR4 as novel biomarkers predicting axillary lymph node metastasis in $\mathrm{T} 1$ breast cancer. Clin Cancer Res 11(16): 5686-5693, 2005.

7 Zhang Z, Ni C, Chen W, Wu P, Wang Z, Yin J, Huang J and Qiu F: Expression of CXCR4 and breast cancer prognosis: a systematic review and meta-analysis. BMC Cancer 14: 49, 2014.

8 Chu QD, Holm NT, Madumere P, Johnson LW, Abreo F, Li BD: Chemokine receptor CXCR4 overexpression predicts recurrence for hormone receptor positive, node-negative breast cancer patients. Surgery 149: 193-199, 2011.

9 Shim H, Lau SK, Devi S, Yoon Y, Cho HT and Liang Z: Lower Expression of CXCR4 in lymph node metastases than in primary breast cancers: potential regulation by ligand-dependent degradation and HIF-1 $\alpha$. Biomedical and Biophysical Res Comm 346: 252-258, 2006.

10 Pan MR, Hou MF, Chang HC and Hung WC: Cyclo-oxygenase2 up-regulates CCR7 via EP2/EP4 receptor signalling pathways to enhance lymphatic invasion of breast cancer cells. J of Biol Chem 283(17): 11155-11163, 2008.

11 Zhang W, Shi HY and Zhang M: Maspin Overexpression modulates tumor cell apoptosis through the regulation of Bcl-2 family proteins. BMC Cancer 5: 50, 2005.

12 Umekita Y, Ohi Y, Sagara Y and Yoshida H: Expression of Maspin predicts poor prognosis in breast cancer patients. Int $\mathrm{J}$ Cancer 100: 452-455, 2002.

13 Mohsin SK, Zhang M, Clark GM and Craig Allred D: Maspin expression in invasive breast cancer: association with other prognostic factors. J Pathol 199: 432-435, 2003.

14 Joensuu KM, Leidenius MH, Andersson LC and Heikkilä PS: High expression of Maspin is associated with early tumor relapse in breast cancer. Human Pathology 40: 1143-1151, 2009. 
15 Wolf AM, Wolf D, Steurer M, Gastl G, Gunsilius E and GrubeckLoebenstein B: Increase in regulatory T-cells in the peripheral blood of cancer patients. Clin Canc Res 9: 606-612, 2003.

16 Gupta S, Joshi K, Wig JD and Arora SK: Intratumoral FOXP3 expression in infiltrating breast carcinoma. Its association with clinic-pathologic parameters and angiogenesis. Acta Oncologica 46: 792-797, 2007.

17 Merlo A, Casalini P, Carcangiu ML, Malventano C, Triulzi T, Menard S, Tagliabue E and Balsari A: FOXP3 Expression and overall survival in breast cancer. J Clin Oncol 27: 1746-1752, 2009.

18 Mansfield AS, Heikkilä PS, Vaara AT, von Smitten KA, Vakkila JM and Leidenius MH: Simultaneous FOXP3 and IDOexpression is associated with Sentinel Lymph Node Metastases in Breast Cancer. BMC Cancer 9: 231-241, 2009.

19 Strien L, Leidenius $M$, von Smitten $K$ and Heikkilä $P$ : Concordance between HER-2 and steroid hormone receptor expression between primary breast cancer, sentinel node metastasis and isolated tumor cells. Pathol Res Pract 206: 253258,2010 .

20 Goldhirsch A, Wood WC, Coates AS, Gelber RD, Thuerlimann B, Senn HJ and Panel members: Strategies for the subtypesdealing with the diversity of breast cancer: highlights of the St. Gallen International Consensus on the primary therapy of early reast Cancer 2011. Ann Oncol 22: 1736-1747, 2011.

21 Perou CM, Sørlie T, Eisen MB, van de Rijn M, Jeffrey SS, Rees CA, Pollack JR, Ross DT, Johnsen H, Akslen LA, Fluge O, Pergamenschikov A, Williams C, Zhu SX, Lønning PE, Børresen-Dale AL, Brown PO and Botstein D: Molecular portraits of human breast tumors. Nature 406: 747-752, 2000.

22 Ladoire S, Arnould L, Mignot G, Coudert B, Rébé C, Chalmin F, Vincent J, Bruchard M, Chauffert B, Martin F, Fumoleau P and Ghiringhelli F: Presence of FOXP3 expression in tumor cells predicts better survival in HER2-overexpressing breast cancer patients treated with chemotherapy. Breast Canc Res Treat 125: 65-72, 2011.

23 Salvucci O, Bouchard A, Baccarelli A, Deschenes J, Sauter G, Simon R, Bianchi R and Basik M: The role of the CXCR4receptor expression in breast cancer: a large tissue micro array study. Breast Cancer Res and Treat 97: 275-283, 2006.

24 Andre F, Cabioglu N, Assi H, Sabourin JC, Delaloge S, Sahin A, Broglio K, Spano JP, Combadiere C, Bucana C, Sorioi JC and Cristofanilli M: Expression of chemokine receptors predicts the site of metastatic relapse in patients with axillary lymph node positive breast cancer. Ann Oncol 17: 945-951, 2006.

25 Kato M, Kitayama J, Kazama S and Nagawa H: Expression pattern of CXC chemokine-receptor-4 is correlated with lymph node metastases in human invasive ductal carcinoma. Breast Cancer Res 5: R144-150, 2003.

26 Kang H, Watkins G, Douglas-Jones A, Mansel RE and Jiang WG: The Elevated Level of CXCR4 is correlated with nodal metastasis in human breast cancer. Breast 14(5): 360-367, 2005

27 Cabioglu N, Sahin AA, Morandi P, Meric-Bernstam F, Islam R, Lin HY, Bucana CD, Gonzalez-Angulo AM, Hortobagyi GN and Cristofanilli M: Chemokine receptors in advanced breast cancer: differential expression in metastatic disease sites with diagnostic and therapeutic implications. Ann Oncol 20: 1013-1019, 2009.

28 Zhao H, Guo L, Zhao H, Zhao J, Weng H and Zhao B: CXCR4 Over-expression and survival in breast cancer: a system-review and meta-analysis. Oncotarget 6(7): 5022-5040, 2015.
29 Kochetkova M, Kumar S and McColl SR: Chemokine receptors CXCR4 and CCR7 promote metastasis by preventing anoikis in cancer cells. Cell Death and Diff 16: 664-673, 2009.

30 Zou Z, Anisowitz A, Hendrix MJ, Thor A, Neveu M, Sheng S, Rafidi K, Seftor E and Sager R: Maspin, a serpin with tumor suppressing activity in human mammary epithelial cells. Science 263: 526-529, 1994.

31 Maass N, Nagasaki K, Ziebart M, Mundhenke C and Jonat W: Expression and regulation of tumor supressor Maspin in breast cancer. Clin Breast Cancer 3(4): 281-287, 2002.

32 Maass N, Biallek M, Rösel F, Schem C, Ohike N, Zhang M, Jonat $\mathrm{W}$ and Nagasaki $\mathrm{K}$ : Hypermethylation and histone deacetylation lead to silencing of the Maspin gene in human breast cancer. Biochem and Biophys Res Comm 297: 125-128, 2002.

33 Beltran AS, Russo A, Lara H, Fan C, Lizardi PM and Blancafort P: Suppression of breast tumor growth and metastasis by an engineered transcription factor. PLOS One 6(9): e24595, 2011

34 Vecchi M, Confalonieri S, Nuciforo P, Vigano MA, Capra M, Bianchi M, Nicosia D, Bianchi F, Galimberti V, Viale G, Palermo G, Riccardi A, Campanini R, Daidone MG, Pierotti MA, Pece S and Di Fiore PP: Breast cancer metastases are molecularly distinct from their primary tumors. Oncogene 27: 2148-2158, 2008.

35 Zuo T, Liu R, Zhang H, Chang X, Liu Y, Wang L, Zheng P and Liu Y: FOXP3 is a novel transcriptional repressor for the breast cancer oncogene SKP2. J Clin Invest 117(12): 3765-3773, 2007.

36 Ladoire S, Mignot G, Dalban C, Chevriaux A, Arnould L, Rébé C, Apetoh L, Boidot R, Penault-Llorca F, Fumoleau P, Roché H, Spielmann M, Levy C, Lortholary A, Eichler F, Mesleard C, Bonnetain $\mathrm{F}$ and Ghiringhelli F: FOXP3 expression in cancer cells and antracyclines efficacy in patients with primary breast cancer treated with adjuvant chemotherapy in the phase III UNICANCER -PACS 01 Trial. Ann Oncol 23: 2552-2561, 2012.

37 Douglass S, Meeson P, Overbeck-Zubrzycka D, Brain JG, Bennett MR, Lamb TW, Browell D, Ali S and Kirby JA: Breast cancer metastasis: demonstration that FOXP3 regulates CXCR4 expression and the response to CCL12. J Pathol 234: 74-85, 2014.

38 Zuo T, Wang L, Morrison C, Chang X, Zhang H, Li W, Liu Y, Wang Y, Liu X, Chan MW, Liu JQ, Love R, Liu CG, Godfrey V, Shen R, Huang TH, Yang T, Park BK, Wang CY, Zheng P and Liu Y: FOXP3 is an X-linked breast cancer suppressor gene and an important repressor of the HER-2/ Erb B2 oncogene. Cell 129: 1275-1286, 2007.

39 Takenaka M, Seki N, Toh U, Hattori S, Kawahara A, Yamaguchi T, Koura K, Takahashi R, Otsuka H, Takahashi H, Iwakuma N, Nagakawa S, Fujii T, Sasada T, Yamaguchi R, Yano H, Shirouzu $\mathrm{K}$ and Kage MO: FOXP3 expression in tumor cells and tumorinfiltrating lymphocytes is associated with breast cancer prognosis. Mol and Clin Oncol 1: 625-632, 2013.

40 Won KY, Kim HS, Sung JY, Kim GY, Lee J, Park YK, Kim YW and Lim SJ: Tumoral FOXP3 has potential oncogenic function in conjunction with the tumor suppressor protein and infiltrated Tregs in human breast carcinomas. Pathology-Res and Pract 209: 767-773, 2013 